\title{
Logical and Illogical Exegeses of Hydrometeorological Phenomena in Ancient Greece
}

\section{Koutsoyiannis, N. Mamassis, and A. Tegos}

Dept. of Water Resources, Sch. of Civil Eng., National Technical Univ. of Athens, dk@itia.ntua.gr

\begin{abstract}
Technological applications aiming at the exploitation of the natural sources appear in all ancient civilizations. The unique phenomenon in the ancient Greek civilization is that technological needs triggered physical explanations of the natural phenomena and behaviours, thus enabling the foundation of philosophy and science. Among these, the study of hydrometeorological phenomena had a major role. This study begins with the lonian philosophers in the seventh century B.C., continues in classical Athens in the fifth and fourth centuries B.C., and advances and expands through the entire Greek world up to the end of Hellenistic period, when Romans conquered Greece. Many of the theories developed in the course of ancient Greek civilization are erroneous according to modern views. However, many elements in Greek exegeses and interpretations of various hydrometeorological processes, such as the evaporation and condensation of vapour, the creation of clouds, hail, snow and rainfall and the evolution of hydrological cycle, are impressive even today.
\end{abstract}

Keywords Ancient Greece; hydrology; meteorology; science; technology.

\section{Introduction}

In all ancient civilizations the exploitation of the natural sources, such as sun, wind and water, was a major activity triggering cultural progress through inventions and technological advances. These achievements helped ancient communities to manage the wind for sailing, to exploit the water for drinking and irrigation and to take advantages of the solar energy by appropriate orientation of buildings. Such technological applications certainly imply some understanding of the nature and the behaviour of these natural elements. However, at the first stages this understanding was primitive and the related explanations were hyperphysical, i.e. mythological.

In ancient Greece, the eternal struggle of humans to control the natural powers has been imprinted in a rich mythology which was survived in texts as well as in artefacts. For example several myths related to Hercules (Heracles), the polymorphic and diachronic hero of ancient Greeks, symbolize the struggle against the destructive power of water. The myth depicted in Figure 1 is related to the duel between Achelous (or Acheloos) and Hercules. Achelous, the greatest (in discharge) river of Greece, in mythology was deified as the son of Poseidon, the god of the sea. Achelous was eventually defeated by Hercules (surrendered after Hercules cracked his horn). As demystified later by the historian Diodoros Siculus (IV 35 ) and the geographer Strabo (X 458-459), the meaning of the victory is related to the channel excavation and the construction of dikes to confine the shifting bed of Achelous. 
With the advancement of technology, a new need arose, the physical exegesis of hydrometeorological phenomena that govern the natural sources (wind, rain, sun). In ancient Greece, several theories were proposed in an environment that lasted for more than six centuries (roughly from Archaic to Roman Period), in which mental activities flourished. This environment has been credited as the birthplace of philosophy and science as both appeared there for first time in history (Krutwig Sagredo, 2006).

Reviewing the original texts of this period, the researcher meets a great variety of theories that extended from mythological explanations based on epics (Homer, Hesiodus), to scientific views. Inside this prosperity, the modern investigator can perceive mythical, poetical, religious, symbolical, philosophical and scientific views. Interestingly, the mythological and symbolical views have been popular even in the late stages of this period, even thought scientific theories had already been developed. This is depicted for instance in the Wind Tower, a monument built in Athens in the 2 nd or $1^{\text {st }}$ century B.C., where the winds are shown as deities (Fig. 2).

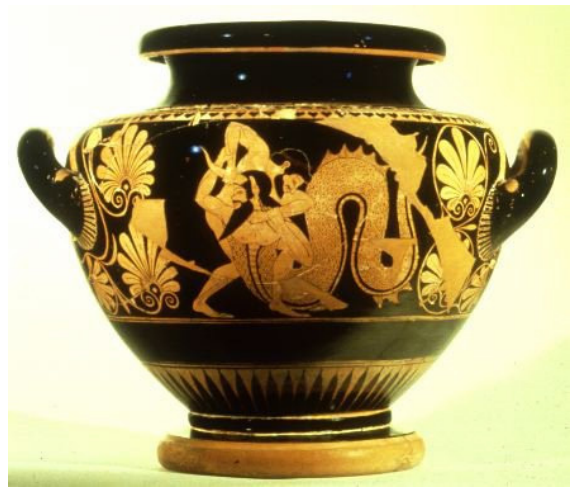

Figure 1 Attic red figure vase, 6th century B.C. depicting the battle of Hercules against Achelous (British Museum).

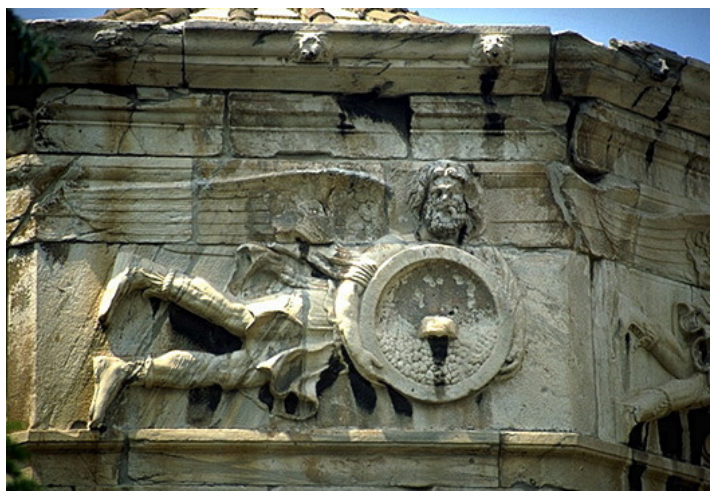

Figure 2 Detail of the Wind Tower in Athens showing Kaikias, the northeast wind holding a shield with hail-stones [Available online at: www.stoa.org/athens/sites/romagora/source/p06 059.html].

Today even the scientific views of ancient Greeks are not useful for the explanation of the hydrometeorological phenomena. The modern scientific basis is very solid (even though several phenomena are not fully understood until today) and seems to be totally independent of the ancient Greek scientific views. However the study of the ancient science is still useful because it reveals that thinking and reasoning, which were the main tools of ancient philosophers (in contrast to modern modelling tools and computers), can establish consistent views of the world, whose precision in some cases is admirable even today (even though in some other cases the views are illogical according to modern knowledge). And also because it enlightens the continuity of the development of science as it is known that the ancient Greek ideas had a major contribution in the beginnings of modern science (during the Renaissance).

Although the modern world inherited many original texts of the ancient Greek civilization, the majority of them have been lost. The next sections focus on the views on hydrometeorological phenomena that come mainly from original texts and cover three phases of the ancient Greek philosophy: the scientific views of the Ionian philosophers, those developed in classical Athens, with emphasis to Aristotle's influential perception of the 
universe, and the advanced developments of the Hellenistic period, with emphasis on the theories of Epicurus.

\section{Ionian Philosophers}

Although the technological application in water resources started before 2,000 B.C., in the Minoan civilization, and continued later in the Mycenaean civilization (Koutsoyiannis and Angelakis, 2003), the first scientific views of phenomena were formulated only around 600 B.C. Greek philosophers from the Ionia region (at the east coast of the Aegean Sea), rejected the prevailing hyperphysical approaches of that period that were reflected in epic poems (mostly in Homer's Iliad and Odyssey), and explained many physical phenomena in a scientific manner.

Thales of Miletus (640-54】 B.C.), one of the Seven Sages of Greece, was the founder of the Ionic philosophy (and according to many, the father of philosophy and of science). Interestingly, his record includes also some engineering achievements thus emphasising the link of technology and philosophy in the genesis of the latter. According to the historian Herodotus (480-430 B.C.; Histories, Cleo, 75) he accomplished the diversion of Ales river in order to help the army of Croesus (king of Lydia) in a conflict against the army of Cyrus (king of Persia). Thales and other Ionian philosophers formulated the theory that the water is the fundamental substance of the world.

Anaximenes (585-525 B.C.), another philosopher from Miletus, devised logical explanations for the formation of clouds, rain and hail (Koutsoyiannis and Xanthopoulos, 1999). According to him

"hail is produced when precipitating water from clouds freezes; snow is produced when the water in the clouds freezes"

Also, of particular importance is the explanation of Anaximenis for the creation of winds:

"they are caused when the air density is decreased, so the air becomes light and then starts to move"

Finally, he gave an explanation for the formation of the rainbow (iris) and attempted to explain lightning (Georgoulis, 1957b).

The philosopher Anaxagoras of Clazomenae (500-428 B.C.) has been very influential; as he lived mostly in Athens, he transplanted the ideas of Ionian philosophers to Athenians including the great politician Pericles, who was his student, the famous dramatists Euripides and Sophocles, and the historian Herodotus. As a natural philosopher and founder of experimental research, he clarified the concept of the hydrologic cycle and studied various meteorological phenomena (winds, storms) generally accepting and completing the explanations of Anaximenes. Specifically, he considered that the differences in the air density, caused by the solar heat, were responsible for the creation of winds (Georgoulis, 1957a). Also, he explained the rainbow (iris):

"iris is the reflection of the solar light incident to the clouds"

Finally, he tried to explain a popular hydrological "paradox" of this period, the floods of the Nile River. The fact that the Nile floods occur at the summertime when rainfall in Egypt is minimal, puzzled the ancient philosophers. Anaxagoras's explanation was that the snow melting in the mountains of Ethiopia in spring, causes summer floods in the regions of Delta of the Nile, with time delay. This explanation is related by Herodotus (Histories, Euterpe), from whom we also know that it was accepted by Euripides and Aeschylus. Herodotus also presents two additional explanations, a mythical one, based on Homer (the floods are produced as the Nile originates from the Ocean, a mythical river located in the Sky) and a more physical, attributed to Thales. According to the latter, the main cause of the floods was 
the northern wind that prevails in the region in wintertime and does not permit the river to flood. During summertime, because of the attenuation of the winds, the river outflows. Obviously, none of these explanations is correct; the ancient Greek philosophers were not aware of the tropical storms in summertime. But what is more important than a correct explanation is the fact that the question is put and studied. Herodotus himself does not adopt any of these explanations. In addition, he appears to understand the processes of hydrologic cycle, such as the evaporation under the influence of heat, the condensation of water vapour and the formation of rainfall.

\section{Philosophers in Classical Athens}

As mentioned above, Anaxagoras is regarded as the link between the Ionian philosophers and Athens. However, the founder of Athenian philosophy is regarded to be Socrates ( $c a$. 470399 B.C.), who is also widely credited for laying the foundation for Western philosophy. Socrates did not write anything himself; however, his student Plato (ca. 427-ca. 347 B.C.) has conveyed some of his teacher's views in his Dialogues, in which Socrates is often a character.

Plato was one of the most influential philosophers and the founder of the Academy in Athens. Despite the great importance of Plato's views in metaphysics, epistemology, politics and ethics, his contribution in natural philosophy is disputable. He is responsible for an erroneous view of the hydrologic cycle, influenced by Homer's epics. For example, in his dialogue Phaedo, he expresses the following view which he attributes to Socrates:

"One of the chasms of the earth is greater than the rest, and is bored right through the whole earth; this is the one which Homer means when he says 'Far off, the lowest abyss beneath the earth' and which elsewhere he and many other poets have called Tartarus.

For all the rivers flow together into this chasm and flow out of it again, and they have each the nature of the earth through which they flow. And the reason why all the streams flow in and out here is that this liquid matter has no bottom or foundation. [...] And when the water retires to the region which we call the lower, it flows into the rivers there and fills them up, as if it were pumped into them; and when it leaves that region and comes back to this side, it fills the rivers here; [...] Thence they go down again under the earth [...] and flow again into Tartarus". Phaedo (14.112)

Interestinly, this, indeed erroneous, view was adopted by many thinkers and scientists from Seneca (ca. 4 B.C.-65 A.D.) to Descartes (1596-1650).

Aristotle (384-328 B.C.) was a student of Plato but the theories he developed are far different from those of his teacher. Aristotle was influenced by Ionian philosophers to develop his own view of the world. His famous treatise 'Meteorologica' is a great contribution to the explanation of hydrometeorogical phenomena. According to Aristotle, there are four principles (hot, cold, dry and liquid), that are combined in order to create the four basic elementals (bodies) of perceptible world. These are the Earth, the Air, the Fire and the Water. These four elementals are the combinations of dry and cold, hot and humid, hot and dry and liquid and cold, respectively. The arrangement of the four basic elementals is spherical (Fig. 3). The Earth is the internal sphere, encapsulated by the spheres of Water, Air and Fire; but the distinction of the elementals is not rigid because they are mixed, in order to produce all substances and phenomena of perceptible world. Roughly, the four concentric spheres correspond to what we call today lithosphere, hydrosphere, atmosphere, and outer space, respectively. The Earth is motionless and only Uranus is moving, affecting natural phenomena. The creation of meteorological phenomena is due to the existence of exhalation. The Earth, while heated by the sun, produces two types of exhalation, the smoke and the 
vapour. The smoke is hot and dry and originates from the Earth, and the vapour is humid and cold and originates from the water. The smoke is the cause of the creation of winds, while the vapour is the cause of creation of precipitation.

According to Aristotle, the genesis and the direction of winds are related to the dry exhalation (smoke) that emerges from the heat of Sun. Despite that dry exhalation (smoke) rises vertically to the surface of ground, the winds blow at inclined directions. This happens because they follow the circular movement of Uranus that surrounds air. Consequently, while the cause of creation of winds is found on the earth, the cause of their movement is owed to Uranus.

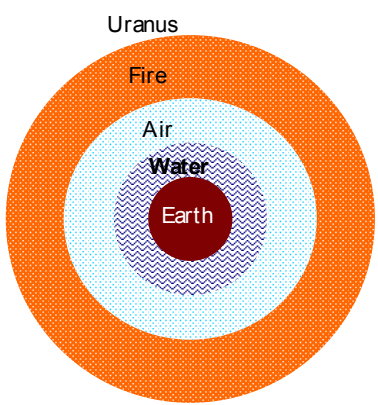

Figure 3 The basic elementals of the world according to Aristotle.

Most of these views are erroneous according to modern knowledge and had already disputed in the Greek antiquity, for instance by the astronomer Aristarchus of Samos (310230 B.C.) who formulated the heliocentric model of the solar system. However, they contain some pieces of truth; for example the recognition of the spherical Earth. In addition, Aristotle formulated correctly the hydrologic cycle (in contrast to Plato). He understood the phase change of water and the energy exchange required for this:

"... the sun causes the moisture to rise; this is similar to what happens when water is heated by fire" (Meteorologica, II.2, 355a 15)

"... the vapour that is cooled, because of lack of heat in the area where it lies, condenses and turns from air into water; and after the water has formed in this way it falls down again to the earth. The exhalation of water is vapour; air condensing into water is cloud." (ibid., I.9, $346 b$ 30)

He also recognized the principle of mass conservation within hydrological cycle:

"Thus, the sea will never dry up; for the water that has gone up beforehand will return to it; and if this has happened once we must admit its recurrence." (ibid., II.3, 356b 26)

"Even if the same amount does not come back every year or in a given place, yet in a certain period all quantity that has been abstracted is returned." (ibid., II.2, 355a 26)

An impressive perception for the world transformation is also included in Aristotle's texts. Specifically, he puts the question whether the extent of land is decreased, compared with that of the sea. Aristotle discusses this question in light of three basic philosophical theses of ancient Greek philosophers. The first is that universe is eternal (Hesiodos, Plato), the second is that is deteriorated (Democritus) and the third is that there is an alternating process (Heraclitus). Aristotle appears to agree with the third opinion. He believes that on large time scales all changes:

"The same parts of the earth are not always wet or dry, but they change depending on the formation or the disappearance of rivers. And so the relation of land to sea changes and a place does not always remain land or sea throughout all time, but where there was dry 
land there comes to be sea, and where there is now sea, there one day comes to be dry land. But we must suppose these changes to follow some order and periodicity." (ibid., I.14, 351a 19)

"... neither the Tanais [the ancient name for the River Don in Russia] nor the Nile has always been flowing, but the region in which they flow now was once dry: for their life has a bound, but time has not. And this will be equally true of all other rivers. But if rivers are formed and disappear and the same places were not always covered by water, the sea must change correspondingly. And if the sea is receding in one place and advancing in another it is clear that the same parts of the whole earth are not always either sea or land, but that all changes in course of time. (ibid., I.14, 353a 16)

The successor of Aristotle in his Peripatetic school, the philosopher Theophrastus (372287 B.C.), adopted and advanced his teacher's theories on the formation of precipitation from condensation and freezing of water vapour. He also understood the relation of winds and cloud formation and the role of the orography on the latter. His contribution in the understanding of the relation between wind and evaporation is widely recognized (Brutsaert, 1982, p. 16).

The above examples indicate the importance of the understanding of meteorological and hydrological processes in classical Athens. We can imagine that the discussions of these issues would be strong and that the acceptance of the new scientific ideas by the public would not be easy because of superstition. These are vividly expressed in the theatre play Clouds (Nefelae) by the comic dramatist Aristophanes (ca. 448 - ca. 385 B.C.). The central character of the play, Strepsiades, a citizen of Athens (whose name means "Twister"), decides to become a student of Socrates to learn rhetoric so he can talk his way out of having to pay his debts. The following passage, a dialogue between Socrates and Strepsiades, is characteristic:

Soc.: $\quad$ What Jupiter? Do not trifle. There is no Jupiter.

Strep.: What do you say? Who rains then? For first of all explain this to me.

Soc.: $\quad$ These to be sure. I will teach you it by powerful evidence. Come, where have you ever seen him raining at any time without Clouds? And yet he ought to rain in fine weather, and these be absent.

Strep.: By Apollo, of a truth you have rightly confirmed this by your present argument. And yet, before this, I really thought that Jupiter caused the rain. But tell me who is it that thunders. This makes me tremble.

Soc.: These, as they roll, thunder.

Strep.: In what way? you all-daring man!

Soc.: When they are full of much water, and are compelled to be borne along, being necessarily precipitated when full of rain, then they fall heavily upon each other and burst and clap.

Strep.: Who is it that compels them to borne along? Is it not Jupiter?

Soc.: By no means, but aethereal Vortex.

Strep.: Vortex? It had escaped my notice that Jupiter did not exist, and that Vortex now reigned in his stead. But you have taught me nothing as yet concerning the clap and the thunder.

Soc.: Have you not heard me, that I said that the Clouds, when full of moisture, dash against each other and clap by reason of their density? (Clouds, 356, English ed. by William James Hickie): 


\section{Philosophers of the Hellenistic Period}

In the Hellenistic period (as the period after the death of Alexander the Great is called), many different schools of thought were developed in the Greek world, among which the most notable were the Sceptics, Stoics and Epicureans. The latter school, which for the first time admitted women and slaves into it, was the one that mostly explored nature and natural phenomena. Its founder Epicurus (341-270 B.C.) represented a departure from the other major Greek thinkers of this and earlier periods. However, he kept several ideas of earlier philosophers. Like Leucippus (first half of 5th century B.C.) and Democritus (ca. $450-c a$. 370 B.C.), he was an atomist, believing that the fundamental constituents of the world are atoms flying through empty space (void) and colliding, rebounding, and becoming entangled with one another. These movements he considered random rather than ordered (linear), thus expressing a view different from the determinism of Leucippus and Democritus and more consistent with the indeterminism of Heraclitus ( $c a .535$ - 475 B.C.). This view allowed the development of notion of free will; according to Epicurus, Gods exist but they do not intervene in natural phenomena or human affairs. His advanced ideas were subsequently (and are even today) misunderstood by many; the most characteristic example is his idea of hedonism, which today has a negative meaning different from that taught by Epicurus. For he explicitly warned against overindulgence because it often leads to pain, whereas the real meaning of hedonism is the absence of physical and mental pain. His epistemological views are remarkable and could stand in a modern discussion, as shown for instance in the following passage (cf. the modern notion of the Theory of Everything):

"It is not good to desire what is impossible, and to endeavour to enunciate a uniform theory about everything; accordingly, we ought not here to adopt the method, which we have followed in our researches into ethics, or in the solution of problems of natural philosophy. [...] We cannot act in the same way with respect to the heavenly phenomena; these productions may depend upon several different causes, and we may give many different explanations on this subject, equally agreeing with the impression of the senses. Besides, it is not here a question about reasoning on new principles, and of laying down, a priori, rules for the interpretation of nature; the only guides for us to follow are the appearances themselves." (Letter to Pythocles, reproduced by Diogenes Laertius, English translation by C.D. Yonge)

Some of his views on the hydrometeorological phenomena and presented in his letter to Pythocles:

"The clouds may be formed either by the air condensed under the pressure of the winds, or by the agency of atoms set apart for the end, or by emanations from the earth and waters, or by other causes. For there are a great number which are all equally able to produce this effect. When the clouds clash with one another, or undergo any transformation, they produce showers; and the long rains are caused by the motion of the clouds when moved from places suitable to them through the air, when a more violent inundation than usual takes place, from collections of some masses calculated to produce these effects." (ibid.)

He also studied, and attempted to explain hurricanes, hail, snow, dew, hoarfrost, rainbow, lightning and thunder; for the time lag between the last two he says:

"... perhaps, the two phenomena being simultaneous, the lightning arrives among us more rapidly than the noise of the thunder-bolt, as is in fact remarked in other cases when we see at an instance the clash of two objects." (ibid.)

From the school of stoics, the philosopher who is known to have studied meteorological phenomena is Posidonius ( $c a .135$ - 51 B.C.) who taught in Rhodes, Athens and Rome. 
Among his writings, all of which are lost except a few fragments, are the treatises "On meteorology" and "On meteors". It is known that he gave explanations on clouds, mist, wind, rain frost, hail, rainbow and lightning, closely following the teachings of Aristotle.

The Hellenistic period signifies the transformation of science to a more rigorous basis, closer to its modern sense. Thus, in this period one can trace the foundation of modern mathematics by Euclid (ca. 325 - 265 B.C.), Archimedes (287 - 212 B.C.) and Apollonius (ca. 262 - ca. 190 B.C.), and the modern astronomy by Aristarchus of Samos (already mentioned above) and Eratosthenes (276 B.C. - 194 B.C.). Archimedes is also considered as a physicist and engineer and the founder hydrostatics. He introduced the principle, named after him, that a body immersed in a fluid is subject to an upward force (buoyancy) equal in magnitude to the weight of fluid it displaces.

Another famous mathematician, physicist and engineer of the late Hellenistic period is

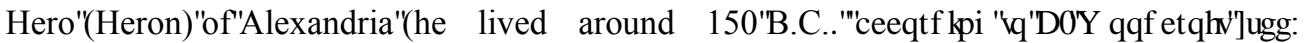
http://www.history.rochester.edu/steam/hero/translators.html] or, according to other references, during 10-70 A.D.; note that the Greek ruled in Egypt up to 30 A.D. when the Roman emperor Augustus conquered it from Queen Cleopatra). In his treatise Pneumatica he founded several physical concepts with their modern meanings such as pressure (air pressure, water pressure, and the connection of the two), flow velocity and discharge. His views are impressing and his experimental method very modern, as revealed from the following passage:

"Vessels which seem to most men empty are not empty, as they suppose, but full of air. Now the air, as those who have treated of physics are agreed, is composed of particles minute and light, and for the most part invisible. If, then, we pour water into an apparently empty vessel, air will leave the vessel proportioned in quantity to the water which enters it. This may be seen from the following experiment. Let the vessel which seems to be empty be inverted, and, being carefully kept upright, pressed down into water; the water will not enter it even though it, it be entirely immersed: so that it is manifest that the air, being matter, and having itself filled all the space in the vessel, does not allow the water to enter. Now, if we bore the bottom of the vessel, the water will enter through the mouth, but the air will escape through the hole. [...] Hence it must be assumed that the air is matter. The air when set in motion becomes wind (for wind is nothing else but air in motion), and if, when the bottom of the vessel has been pierced and the water is entering, we place the hand over the hole, we shall feel the wind escaping from the vessel; and this is nothing else but the air which is being driven out by the water. It is not then to be supposed that there exists in nature a distinct and continuous vacuum, but that it is distributed in small measures through air and liquid and all other bodies. [...] Winds are produced from excessive exhalation, whereby the air is disturbed and rarefied, and sets in motion the air in immediate contact with it. This movement of the air, however, is not everywhere of uniform velocity: it is more violent in the neighbourhood of the exhalation, where the motion began." (Pneumatica, Treatise, English translation by Bennet Woodcroft)

Hero was able to convert his theoretical knowledge into technological inventions. Thus, in his writings he describes numerous devices and mechanisms he invented, among which the simplest is the siphon and the most famous is the steam engine or steam turbine (aeolipile; Fig. 4), the first recorded engine exploiting the power of steam, which was created almost two millennia before the industrial revolution. 


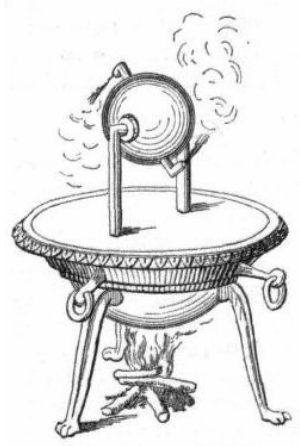

Figure 4 Hero's steam engine.

\section{Conclusion}

Technological applications aiming at the exploitation of the natural sources appear in all ancient civilizations. The unique phenomenon in the ancient Greek civilization is that technological needs triggered physical explanations of the natural phenomena and behaviours, thus enabling the foundation of philosophy and science. Among these, the study of hydrometeorological phenomena had a major role.

Many of the theories developed in the course of ancient Greek civilization are erroneous according to modern views. However, there are many impressive elements in Greek exegeses and interpretations of various hydrometeorological processes, such as the evaporation and condensation of vapour, the creation of clouds, hail, snow and rainfall and the evolution of hydrological cycle. Naturally, at the latest stage of this civilization, the Hellenistic period, the theories developed were more advanced, closer to the modern sense of scientific theories, and reveal better understanding of physics. The latter theoretical advances enabled a significant technological progress, which however soon after was discontinued, its potential only to be realized during or after the Renaissance.

\section{References}

Brutsaert W. (1982). Evaporation into the Atmosphere. Reidel, Dordrecht.

Georgoulis K.D. (1957a). Anaxagoras. Entry in Helios Encyclopedia, Engyclopaidikes Epitheoresis Helios, Athens, Greece, 2, 680-688.

Georgoulis K.D. (1957b). Anaximenes. Entry in Helios Encyclopedia, Engyclopaidikes Epitheoresis Helios, Athens, Greece, 2, 694-696.

Koutsoyiannis D. and Xanthopoulos T. (1999). Engineering Hydrology. $3^{\text {rd }}$ ed., National Technical University of Athens, Athens, Greece, (in Greek).

Koutsoyiannis D. and Angelakis A.N. (2003). Hydrologic and hydraulic science and technology in ancient Greece. The Encyclopedia of Water Science, Dekker, New York, USA, 415-417.

Krutwig Sagredo F.C. (2006). El Milagro Griego. Jakintza Baitha (Greek Translation: Ekdotiki Thessalonikis). 